\title{
The Impact of Agile Methods on the Development of an Agile Culture - Research Proposal
}

\author{
[The Agile Evolution] \\ Steffen Küpper \\ Technische Universität Clausthal \\ Institute for Applied Software Systems Engineering \\ Wallstr. 6 \\ 38640 Goslar, Germany \\ steffen.kuepper@tu-causthal.de
}

\begin{abstract}
Today, establishing agile methods and an agile organisational culture in parallel is a commonly accepted prerequisite for the success of agile in organisations. Latest research show a correlation between agile methods and agile culture. Less discussed in Software Engineering is how the realisation of agile methods affects the development of an agile culture.

The aim of this $\mathrm{PhD}$ research is to investigate how the impact of agile methods on the development of an agile culture can be identified, described and measured.

The research follows qualitative research methods, e.g. grounded theory. In the first phase, semi-structured interviews have been conducted among experienced agile coaches, structured analysis techniques have been applied to develop well-grounded theories, and the systems thinking approach will be used to create a system model. The second phase will use the DELPHI-method to validate the theories and the model. This paper presents my motivation, basic assumptions and describes my research methodology with the status of my research. At the end I propose a roadmap for the second phase of my $\mathrm{PhD}$ research and conclude with preliminary findings.
\end{abstract}

\section{Keywords}

agile culture, organisation, qualitative methods, Grounded Theory, Systems Thinking, impact practices, agile maturity

\section{MOTIVATION}

Agile! Today, organisations use this term synonymously for increasing productivity, faster time-to-market, more flexibility, etc. In other words, for organisations agile is a promise for something better just by changing the development processes. The challenge is to decide how to implement agile. Organisations have to choose among a large variety of agile processes, methods and tools. Additionally, there are several

ACM acknowledges that this contribution was authored or co-authored by an employee, contractor or affiliate of a national government. As such, the Government retains a nonexclusive, royalty-free right to publish or reproduce this article, or to allow others to do so, for Government purposes only.

EASE '16, June 01-03, 2016, Limerick, Ireland

(C) 2016 ACM. ISBN 978-1-4503-3691-8/16/06 .. \$15.00

DOI: http://dx.doi.org/10.1145/2915970.2915977 approaches to introduce agile. Depending on the organisation's situation agile starts either as a grass roots movement or as a top-down management decision. Both approaches provide pros and cons, opportunities and borders, but neither one is a guarantee for success or failure. Still, organisations have to decide if agile should be introduced at once or stepwise. Finally, all these approaches can be combined as necessary.

However, agile also leads to resistance. Involved people may perceive agile as an affront. Working principles and values, evolved over years, are questioned and seem to be not appropriate any longer. In fact, some agilists emphasise that "agile is a culture, not a set of practices" [2] and that "whether a site is Agile or not depends on its culture" [3]. Still, insights on how to establish an agile culture are rare. Recommendations are mainly limited to installing a Transition Team, authorising external coaches or just strictly apply agile practices like Retrospectives.

Meanwhile it is commonly accepted, that establishing an agile culture in parallel with agile development processes is a prerequisite for succeeding with agile. Some latest research show a correlation between methods and culture [5], [7], [8], [12], [17], [18], [19]. Less discussed in Software Engineering is how the realisation of agile methods affects the development of an agile culture.

This may also be an explanation why much of the explications on agile in industry still focus on process-related aspects, while culture is considered less important or even unimportant. During a conference in 2015 I was able to experience, that the need for such linking explanations is quite present: A large company explained that they clearly know how to apply agile practices. What they would like to discuss was, how they could establish agile across the complete organisation and employees.

The goals of my $\mathrm{PhD}$ thesis are to detect new insights on (1) the correlation between agile practices and agile culture as well as (2) the structure of the path to agile when practices and culture are considered. For me, analysing the behaviour of organisations is a key aspect to investigate (1) and (2). To achieve these goals, I will use qualitative research methods to develop well-grounded theories [6] as well as the systems thinking approach [20] to describe the correlations.

\section{ASSUMPTIONS AND RELATED WORK}

In my opinion, emphasising that agile is a culture and not 
a set of practices is too narrow. Even if this statement most likely aims at drawing attention to the fact, that culture is an important aspect.

The basic assumption for my $\mathrm{PhD}$ thesis is somewhat broader: Agile is the establishment of agile processes and practices together with a supportive agile culture. If both aspects do not support each other, agile is possibly to fail. As Robert Martin emphasises: "Agile is a culture expressed through a set of practices" [10].

As a consequence, agile can be described with the help of organisational cultural models, e.g. Edgar Schein's organisational culture model [14] or Geert Hofstede's cultural onion [13]. Organisational cultural models are approaches to describe relations between members of a group and to characterise the identity and the outside of a group. They provide meaning and structure to everyday work and a reference for a cultural change. Common for these models is that they describe multiple cultural levels. The top levels refer to observable and conscious actions, easily described by techniques, artefacts and standards. The lowest levels describe the perception of culture. They represent values, abstract concepts and intuitive actions, which are not easy to observe and to describe accurately. Levels in between describe the gradations. The levels need to be aligned to have a well-functioning organisation. This representation should help to describe what organisations have to achieve, when they truly want to become agile.

The limit of a cultural model is that it only can describe culture at the time it is observed and define the desired culture of an organisation. Thus, another representation is necessary to understand the path organisations follow to establish agile and what actions lead to success or failure. Maturity Models describe this path, e.g. Capability Maturity Model Integration (CMMI). CMMI is certainly not limited to non-agile development processes. On the contrary, CMMI underlines explicitly that it is appropriate for agile [15]. Nevertheless, a major focus of CMMI is still the development and standardisation of processes. In order to address particularly the establishment of agile, different Agile Maturity Models (AMM) have been developed. Striking is, that they are mostly influenced by CMMI [15] and describe the path from a technical perspective. Only the Agile Adoption Framework from Sidky [1] links agile values and principles with practices. But still Sidky's goal is to provide an answer to the question: "how to adopt agile practices" [1, p. 5].

The two concepts, cultural models and maturity models, are linking the path with the desired state agile. Still missing are concrete actions to describe how organisations can control the path. Agile practices provide detailed instructions for the user, describing what to do and when. For example, Daily Scrum requires every team member attending the meeting every time. Looking at the cultural model, this instruction (top level) can be understood as an observable representation of the principle (lower level) "The most efficient and effective method of conveying information to and within a development team is face-to-face conversation."

This reduced example shows: any agile practice is designed deliberately to address an original intention of the agile manifesto and thus links practices with principles and values. One insight is that the concrete realisation of a practice has an influence on the culture. When applying a practice correctly it describes the desired culture. If something

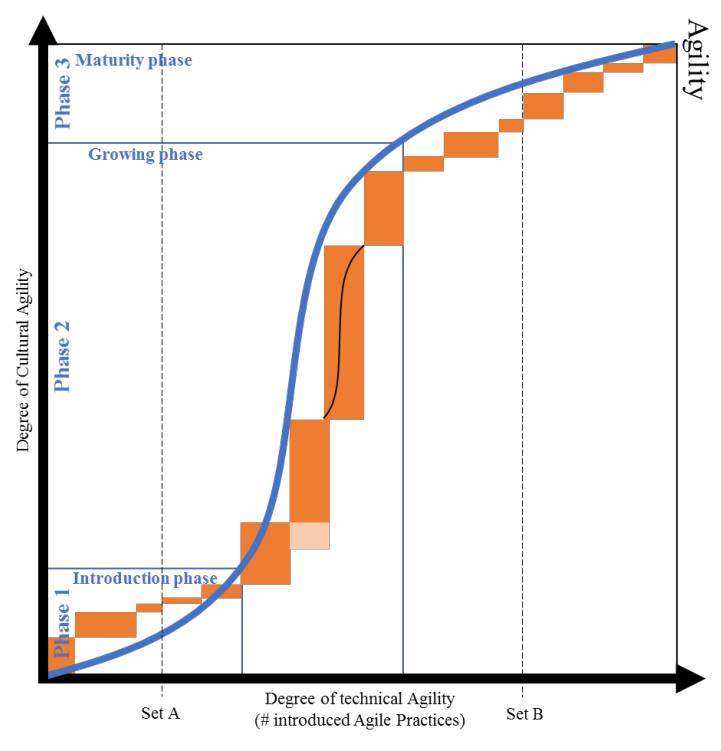

Figure 1: Culture as a dependant function of agile practices [4]

is eliminated, e.g. everyone's presence, either the desired culture is not realised completely (or correctly) or another practice needs to be implemented.

The given example reveals another insight. For each practice I can ask which cultural aspect is addressed, how strong is the impact, do sets of practices have a different impact, etc. Finally, I assume that the order of introducing practices affects the impact on the culture as well. Either it intensifies or it decreases the impact on the agile culture; figure 1 expresses these assumptions.

\section{RESEARCH QUESTIONS}

Two leading research questions for my $\mathrm{PhD}$ thesis arise from my assumptions:

RQ1: How can the agile maturity process of an organisation be described, measured, and assessed?

RQ2: How can the impact of agile practices on the agile culture be described, measured, and assessed?

\section{METHODOLOGY}

I have decided to choose a research method, which allows me to impose data from the agile users' point of view and to densify this to well-grounded theories. Consequently, the leading research paradigm is Grounded Theory [6]. A discussion on the history and classification of Grounded Theory would be too much here. Nevertheless, I will make transparent which conceptual postulates found their way into my research [9, pp. 20-21]; Constant Comparative Method [6], Triangulation [16], and Field Memos [16].

My research is divided into two main phases. The first phase is to generate the theories and models and the second phase is to validate the theories and models using a DELPHI-study.

\subsection{Phase 1: Theory-Generation}

I have decided to conduct semi-structured interviews to collect data to generate theories. I interviewed eight agile 
coaches in Germany with an agile background between 6 and 20 years. Two reasons were decisive for this decision. First, coaches more likely think about the development of an agile culture than organisations, where culture is of minor interest when introducing agile. Second, their experience bases on accompanying multiple organisations with their agile transformations, at several stages and in several environments. What enables coaches to describe typical patterns of behaviour, rather than organisations which mostly can only refer to the own change.

The interviews were conducted in January and February 2016. Each Interview took one hour and was recorded with an audio recorder. The structure of the interview is as follows:

\section{Introduction.}

2. Part 1: How organisations proceed to introduce agile.

3. Part 2: How organisations establish an agile culture.

\section{Recapitulation.}

For each part, additional questions were provided about how, who, when, why, actions, failures and success factors.

Before the analysis a pre-coding was done [16] to create a first coding framework, using concepts Cultural Model and Maturity Model as the heuristic axis [9, p. 21].

Table 1 provides an excerpt from the coding framework and can be read hierarchically. Top level are the Categories, that represent the concepts, e.g. Agility describes what agile is. The next level are the Coding families, they describe all elements of the concept, e.g. Goal of Agility describes typical goals organisations want to achieve with agile. The lowest level contains all Codes, which are the indicators to describe the elements, e.g. Transparency is one specific goal organisations want to achieve with agile.

I decided to use Summarizing and Structuring accordingly to Mayring [11] as analysing techniques. The Summarizing was conducted in two steps:

1. Categorising the interviews: analysing each line and assign it to an appropriate Category.

2. Encoding the interviews: assigning each finding to the appropriate Code.

The interviews were encoded one by one, following the above-described steps, and the findings incrementally completed [9, p. 21]. If data could not be assigned to an existing Code, a new Code, Coding family, or Category was added to the coding framework; Codes were rearranged as necessary (post-coding [16]). After, already analysed interviews were analysed again. At the end, the findings are paraphrased to a comparable level of abstraction.

The next step is to summarise the findings assigned to a Code and condense them to a statement. Negative or contradictory findings are either evidence for abandonment or require a reformulation of the already created statement. After, the statements are used to describe the elements (Coding family) of the concept (Category), thus the theory w.r.t. the heuristic axis is developed [9, p. 21].

Correlations and relationships are not the focus of the Summarizing. Thus, the Structuring will be done next. This technique operates in three steps, defining categories (by adding structural dimensions and characteristics to the
Table 1: Excerpt of the coding framework after the pre-coding

\begin{tabular}{l|l|l}
\hline Category & Coding family & Codes \\
\hline Agility & Goal of Agility & $\begin{array}{l}\text { Transparency, } \\
\text { React on changes, } \\
\text { Reflection [...] }\end{array}$ \\
\hline Agility & Elements & $\begin{array}{l}\text { Culture, Manage- } \\
\text { ment, Customer } \\
{[\ldots]}\end{array}$ \\
\hline Agile maturity & Maturity process & $\begin{array}{l}\text { Step, Phase (Di- } \\
\text { mensions 1 - n) } \\
{[\ldots]}\end{array}$ \\
\hline Agile maturity & strategy & $\begin{array}{l}\text { Managed, } \\
\text { Unmanaged, } \\
\text { Bottom-Up [...] }\end{array}$ \\
\hline $\begin{array}{l}\text { Impact on Cul- } \\
\text { ture }\end{array}$ & Practices & $\begin{array}{l}\text { Scrum, Kanban, } \\
\text { Backlog [...] }\end{array}$ \\
\hline $\begin{array}{l}\text { Impact on Cul- } \\
\text { ture }\end{array}$ & Degree of impact & $\begin{array}{l}\text { Much, } \\
\text { Quick-Win [...] }\end{array}$ \\
\hline
\end{tabular}

existing coding framework), identify anchor samples to describe the categories, and formulate coding rules [11].

To finish phase 1, the results of both analyses will be compared, consolidated theories written down, and representing models generated using the systems thinking approach [20], until July 2016.

\subsection{Phase 2: Theory-Validation}

To validate the developed theories and models I plan to design and conduct a DELPHI-study. In this study, I want to question the interviewees from the first survey as well as organisations that are currently in the agile transformation or already have finished the transformation. The detailed steps of this phase will be planned, when the results of the first phase exist. Phase 2 will be carried out in the second half of 2016.

Both main phases will be accompanied by publications at conferences and in journals. After finishing the validation, I will finish writing my PhD thesis.

\section{PRELIMINARY FINDINGS}

I will conclude this paper with some preliminary findings, I consider relevant for my further research.

At the end of each interview, I asked the interviewee to assess two aspects of my assumptions. First: (Q1) How do you assess the separation of agile methods and agile culture, w.r.t. your work?

Coaches perceive this separation as an aid to gain insights, identify goals of the agile transformation, and have a reference against which they can check. However, both aspects need to be considered equally, because they "cannot exist independently". For the interviewed coaches practices are means to develop an agile culture. "Practices can be trained and described in books. Culture cannot be trained, or is very difficult to train, so I need practices to really do the other ${ }^{1} . "$ The opinion is, that practices are tools, which need to be realised and trained in order to understand what to do. This supports my assumption that it is also necessary to understand why something is done and that it is is done

\footnotetext{
${ }^{1}$ Meaning the establishment of an agile culture
} 
through a cultural shift as well.

Second: (Q2) How do you assess the idea, that agile culture is a result of a concrete realisation of agile practices?

Basically, the interviewees support this assumption. "I believe that changing practices and methods sooner or later must lead to a cultural change [...], but they are neither adequate nor indispensable." This is because agile, seen from the perspective of the development process, does not provide enough practices to change the complete culture of an organisation, additional practices for Management and/or "non-developing" departments of an organisation are necessary. This indicates that agile practices do have an impact on the agile culture.

Finally, when talking about "getting agile", coaches emphasise that they find orientation in the concept of Shuhari ${ }^{2}$. "Just listen to the Master, if he says do Scrum, just do it, and sometime later you can start thinking about. Even later, you can start to adjust." To summarise, becoming an agile organisation is about copying, learning, and adapting the trained until it becomes the organisations' own identity. Hence, there is a general path to agile which can be described. Together with the evidence of Q1 and Q2 I can describe an evolutionary model, containing more elements than the existing Agile Maturity Models and showing the correlation between agile practices and agile culture in particular.

I believe, that this research provides further insights on the correlation of agile practices and agile culture and a practical use for industry to align their agile practices with the desired effects of agile.

\section{ACKNOWLEDGEMENTS}

I would like to thank my PhD supervisors Prof. Dr. U. Andelfinger (University of Applied Sciences Darmstadt) and Prof. A. Rausch (Technische Universität Clausthal) for their support and constantly pointing on open issues in my work. I also like to thank Malte Mues and Matthias Wiatrok for their coding.

\section{REFERENCES}

[1] Ahmed Sidky. A Structured Approach to Adopting Agile Practices: The Agile Adoption Framework. Phd, Virginia Polytechnic Institute and State University, Virginia, 2007.

[2] Allen Holub. The agile holocracy. http://www.drdobbs.com/architecture-anddesign/the-agile-holocracy/240166629, 2014. Accessed: 2016-03-25.

[3] Andrew Binstock. The corruption of agile. http://www.drdobbs.com/architecture-anddesign/the-corruption-of-agile/240166698, 2014. Accessed: 2016-03-25.

[4] P. Diebold, S. Küpper, and T. Zehler. Nachhaltige agile transition: Symbiose von technischer und kultureller agilit Âd't. In Projektmanagement und Vorgehensmodelle 2015: Hybride Projektstrukturen erfolgreich umsetzen, pages 121-126, 2015.

[5] R. Fontana et al. Processes versus people: How should agile software development maturity be defined. Journal of Systems and Software, 97:140-155, 2014.
[6] B. Glaser and A. Strauss. The Discovery of Grounded Theory: Strategies for Qualitative Research. Aldine, New Brunswick, 4. paperback printing edition, 1999.

[7] M. Hummel and A. Epp. Success factors of agile information systems development: A qualitative study. In 48th Hawaii International Conference on System Sciences (HICSS), pages 5045-5054, 2015.

[8] Jiangping Wan, Weiping Luo, and Xiaoyao Wan. Case study on critical success factors of agile software process improvement. In International Conference on Business Management and Electronic Information (BMEI), pages 628-631, 2011.

[9] U. Kelle. "emergence" vs. "forcing" of empirical data? a crucial problem of "grounded theory" reconsidered. Forum Qualitative Sozialforschung / Forum: Qualitative Social Research, 6(2)(27), 2005. Accessed: 2016-03-25.

[10] R. Martin. The true corruption of agile. http://blog.8thlight.com/uncle-bob/2014/03/28/TheCorruption-of-Agile.html, 2014. Accessed: 2016-03-25.

[11] P. Mayring. Qualitative Content Analysis: Theoretical Foundation, Basic Procedures and Software Solution. Beltz, Klagenfurt, 2014.

[12] S. Misra, V. Kumar, and U. Kumar. Identifying some important success factors in adopting agile software development practices. Journal of Systems and Software, 82(11):1869-1890, 2009.

[13] A. Reimer. Die Bedeutung der Kulturtheorie von Geert Hofstede für das internationale Management, volume 2005,20 of Wismarer Diskussionspapiere. Hochschule Fachbereich Wirtschaft, Wismar, 2005. Accessed: 2016-03-25.

[14] E. Schein. Organizational culture and leadership. Jossey-Bass, San Francisco, Calif., 3. ed. edition, 2004.

[15] T. Schweigert et al. Agile maturity model: Oxymoron or the next level of understanding. In Software Process Improvement and Capability Determination, volume 290, pages 289-294. Springer, Berlin and Heidelberg, 2012.

[16] C. Seaman. Qualitative methods in empirical studies of software engineering. IEEE Transactions on Software Engineering, 25(4), 1999.

[17] D. Strode, S. Huff, and A. Tretiakov. The impact of organizational culture on agile method use. In $42 n d$ Hawaii International Conference on System Science (HICSS), pages 628-631, 2009.

[18] E. van Kelle et al. An empirical study into social success factors for agile software development. In $8 t h$ International Workshop on Cooperative and Human Aspects of Software Engineering (CHASE), pages 77-80, 2015.

[19] Version One. 9th annual state of agile survey. https://www.versionone.com/pdf/state-of-agiledevelopment-survey-ninth.pdf, 2015. Accessed: 2016-03-25.

[20] G. Weinberg. Quality software management: Systems Thinking. Dorset Hous Publ., New York, 1992.

\footnotetext{
${ }^{2}$ A Japanese martial arts training and learning concept.
} 